\section{Multi-Sensory Balance Board for Children with SPD \& ADHD Disorders}

\author{
Shila Amouei*®, Ali Selk Ghafari², Abolghasem Zabihol- \\ lah², Shima Mohammadi Moghaddam³, Zahra Mohammadi \\ Laal Abadi ${ }^{4}$
}

\begin{abstract}
Nowadays, as technology grows, human life formation changes every second. These changes sometimes create harmful habits and affect our lifestyle, which unfortunately bring various diseases and disorders. ADHD (Attention Deficit Hyperactivity Disorder) $\&$ SPD (Sensory Processing Disorder) are common disorders in children. By giving children the right treatment at the younger ages, we can help them overcome their disabilities and not face any symptoms in their adulthood. The multi-sensory balance board is designed and developed to help medics diagnose the disorders in patients at early stages and monitor the treatment progress. The balance board uses multiple sensors to detect common human senses, visual, auditory, balance, and tactile sensing.

Due to the safety issues for children during the COVID-19 pandemic, the balance board has been clinically tested for adults with stroke disorder. The research has concluded that it provides a fast low-cost with reliable results to diagnose the disorders in patients.

Citation: Amouei Sh, Selk Ghafari A, Zabihollah A, Mohammadi Moghaddam Sh, Mohammadi Laal Abadi Z, Kiani A. Multi-Sensory Balance Board for Children with SPD \& ADHD Disorders. J Biomed Phys Eng. 2021;11(6):761-768. doi: 10.31661/jbpe.v0i0.2101-1265.
\end{abstract}

\section{Keywords}

ADHD; Disabled Children; Rehabilitation; Balance board; Stroke

\section{Introduction}

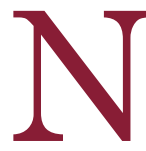

$$
\begin{aligned}
& \text { ew life formation and concerns, in an era in which technology } \\
& \text { is advancing at an incredible rate, cause the lives of many indi- }
\end{aligned}
$$
viduals to be in flux. Unhealthy diet, harmful effects of improper, and excessive use of smartphones and computers in addition to less physical activities have weakened the human body and expanded the possibility of various disabilities. In this regard, ADHD (Attention Deficit Hyperactivity Disorder) and SPD (Sensory Processing Disorder) are two of the most common diseases, particularly among children [1-3].

\section{Balance Disorder}

On a human body, balance is the sign of cooperation between several different body organs, including the visual system (eyes), the vestibular system (ears), and proprioception (the body's sense of where it is in space). Disruption in any of these systems causes an imbalance [4].

The imbalance is the cause of various disabilities such as Stroke, Multiple Sclerosis (MS), ADHD, and SPD in both children and adults [5-8].

There are multiple ways to treat a balance disorder depending on the type of disease. Doctors will recommend different treatments such as balance retraining exercises (vestibular rehabilitation) [9], positioning
${ }^{1} \mathrm{MSc}$, Department

of Mechanics \& Me-

chatronics Engineering,

Sharif University of Tech-

nology (Kish Campus),

Kish, Iran

${ }^{2} \mathrm{PhD}$, Department

of Mechanics \& Me-

chatronics Engineering,

Sharif University of Tech-

nology (Kish Campus),

Kish, Iran

${ }^{3} \mathrm{MSc}$. Department of

Biomedical Engineering,

Sharif University of Tech-

nology, Tehran, Iran

${ }^{4} \mathrm{BSc}$, Department of Re-

habilitation Science, Iran

University of Medical

Science, Tehran, Iran

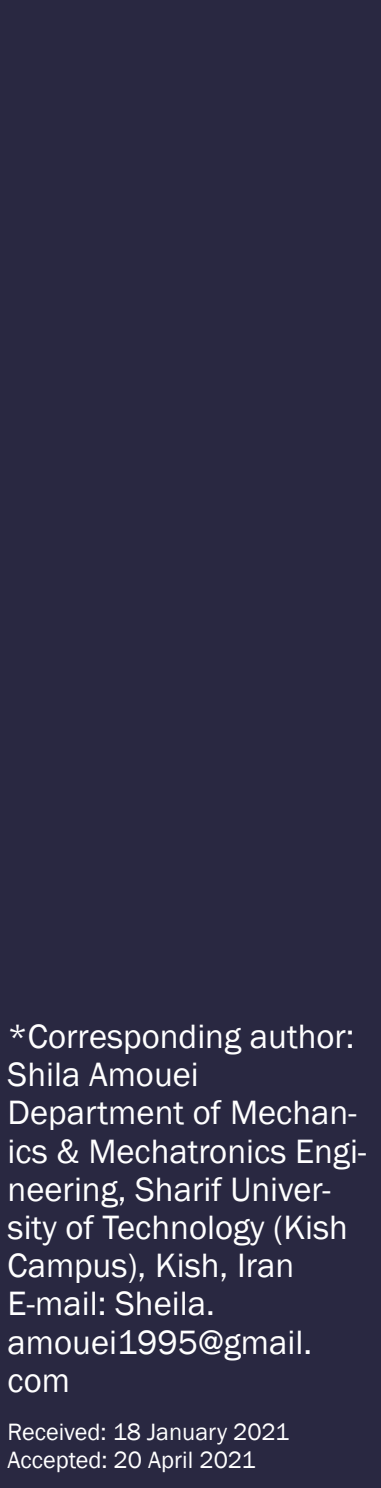


procedures [10], diet, and lifestyle changes [11], medications, and surgery $[12,13]$.

\section{Attention Deficit Hyperactivity Disorder (ADHD)}

ADHD is a common nervous system in the human body, impairing brain development and can occur at different ages. Prenatal, genetic causes and low birth weight have also been implicated, and environmental factors, psychosocial problems, toxins, and diet may be involved $[14,15]$.

There are three main subtypes of ADHD, including predominantly inattentive, oredominantly hyperactive/impulsive, hyperactivity (Combined) [16, 17]

Usually, in children, symptoms, and impairment started by the age of seven. By diagnosis, the treatment and medication procedure can be formed in childhood, containing a higher chance of alleviating the child [18].

Many other effective treatments can help kids with ADHD to improve their ability to pay attention, control impulsive behavior, and curb hyperactivity [19].

\section{Sensory Processing Disorder (SPD)}

Sensory processing disorder is a condition, affecting the processes of brain's sensory information, and deals with the information coming from one or all following sensory systems $[20,21]$.

Difficulties in the processing of this information can lead to numerous essential problems.

There are three possible components of dysfunction of sensory integration:

1) Sensory Modulation Disorder (SMD).

2) Sensory-Based Motor Disorder (SBMD).

3) Sensory Discrimination Disorder (SDD) [22].

The treatment of children struggling with ADHD or SPD should contain:

- Vestibular.

- Ocular movements separate from vestibular and vice versa.

- Proprioceptive (joint and muscle reception, muscle tone, coordination).

- Tactile (processing of light and deep touch).

- Auditory filtering of input.

- Visual processing.

- Reflexes and integration of those reflexes.

- Attention to many differing environments [23-26].

- Balance board for entertainment purposes [27].

Nowadays, doctors and occupational therapies use balance boards in rehabilitation after injury to various parts $[28,29]$. Balance board is a suitable tool for children and can also improve their self-confidence and stability, which is the combination of entertainment and exercises for the development of the sensory integration [30].

There are thousands of models of balance boards available in the market, mainly designed to detect patients' basic balance sense.

In this project, a novel balance board has been developed, in which the patient's sense of balance is combined with other auditory, visual senses, and tactile sensing.

\section{Technical Presentation}

\section{Multi-Sensory Balance Board}

Multi-sensory balance board combines multiple senses to enhance user security through the auditory system and the membrane labyrinths in the inner ear. Since equilibrium reactions occur only after the loss of equilibrium, there is a definite risk of falling, providing the reaction time is extended. An alarm has been embedded in the board to warn the user at the beginning of imbalance. This enhances the patient safety and prevents accidental injuries. Adding sensory visual, and auditory functions to the device makes it an exciting adventure to perform the test. The multi-sensory balance board contains four different parts, including visual, auditory, balance sense, and tactile sensing (transmitted from the foot).

As the user is standing on the balance board struggling to keep his balance, the visual and 
auditory senses are also getting activated; thus, whenever the user's imbalance starts, a specific color light turns on. In addition to the color light, an alarm sound will turn on, enabling the user to use different senses simultaneously. There is also a replaceable touchpad on the board, containing a sense of softness and coarseness (for encouraging tactile sensing).

The user might lose their balance in four different directions, focusing the bodyweight on the front, back, left, or right. There are four different lights with different colors for each direction, causing the user to distinguish the directions to maintain the balance again. If the user's balance is lost in more than one direction, more than one light will turn on. Moreover, there are four more lights that turn on manually by a keypad, providing the ability to activate a specific color light for the occupational therapist. The light helps the user to be observant and move in the lighted direction.

\section{Experimental setting of multi-sen- sory balance board}

Multi-sensory balance board contains three main parts as shown in Figure 1:

1) Balance Board

2) Power Distribution Box

3) Light Display Plate

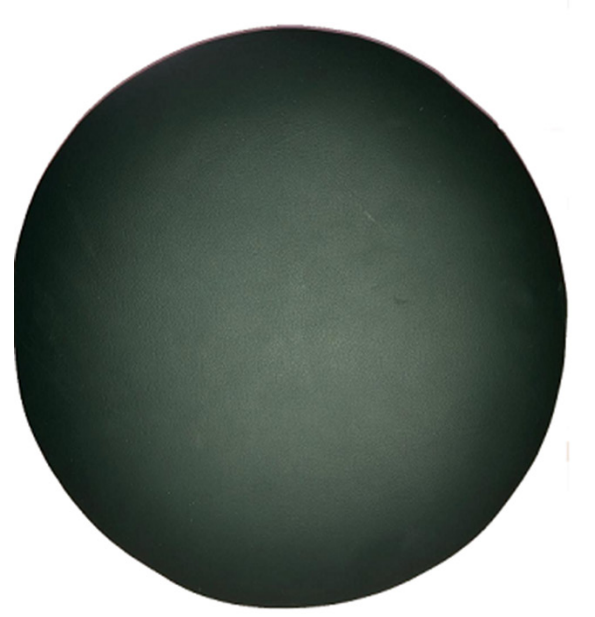

\section{Balance Board}

In this project, one of the first and essential parts is to select the best balance board to work and make it an intelligent device. Various types of balance boards are available in the market. A wobble board with a circular cross-section model is used in the present work, as shown in Figure 1.

Sensor (6-AXIS GYROSCOPE): A 6- axis gyroscope (MPU 6500) has been used to measure the balance board's angle with the ground in three different dimensions.

Springs: Four replaceable springs are designed and mounted on the bottom of the balance board. The spring force causes the users to control their weight on the board more easily (According to Hooke's Law).

Replaceable Touchpads: Interchangeable touchpads are used to stimulate the sense of touch through the soles of the feet.

\section{Power Distribution Box}

The power distribution box is the central part of this device, containing the main electrical components such as the microcontroller, relay modules, speaker, and keypad.

The microcontroller is programmed to turn the lights and activate the speaker.

\section{Light Display Plate}

There are eight different lights divided into two sections. The first section, placed on the

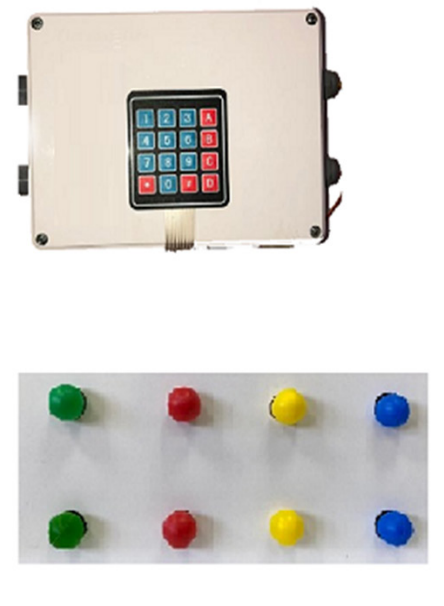

Figure 1: Multi-Sensory Balance Board 
upper row of the display plate, is connected to the keypad. Besides, if the user presses one of the bottoms between $\mathrm{A}$ and $\mathrm{D}$, one of the color lights will turn on. The second section is placed on the bottom row of the display plate, connected to the sensor, and will turn on the user's imbalance.

At present, the multi-sensory balance board has been in the clinical testing stage. Due to the safety issues for children, particularly during the COVID-19 pandemic, the multi-sensory balance board has been used for adults with various disabilities and disorders such as SPD, ADHD, Parkinson, stroke, and even Coronavirus infected people. The clinical tests have been conducted in the neurorehabilitation center in Paras hospital in Iran, located in Tehran, for more than three months.

Table 1: The results of the first stroke groups used in clinical testing.

Each patient's result is divided into two categories, including the sensor's results and the occupational therapists feedback.

The sensor results contain three different graphs for each therapy session of a patient.

Multi-sensory balance board monitors the patient's balance in three different dimensions for higher efficiency and a decrease in the error factor.

In each session, three graphs are available for three different angles (X, Y, Z).

Occupational therapy sessions in stroke patients are usually in a 10 -session package.

\section{Data Analysis}

Patient A is a 36 years old male, who has had a stroke in less than four months. According to his doctor, he suffered from touch and numbness in his left arm and leg after a stroke, thus he could not stand on the balance board with- out help. However, on the first therapy session, he stood on the balance board for about 6 min and $30 \mathrm{~s}$. As it could be realized from the graphs with different angles, the patient faced a major imbalance. In the tenth session (final session), the patients' balance improved significantly, and they were able to stand on the balance board by themselves without any help about five min. Besides, the medical team report has proven that the multi-sensory balance board was useful and significantly improved the patient's rehabilitation progress.

Patient B is a 32 years old male, who has had a stroke in less than a year. According to his doctor, he had tremors in his body after the stroke, especially his legs. Thus, he could stand on the board with trembling. However, on the first therapy session, he could stand on the balance board for about $1 \mathrm{~min}$ and $30 \mathrm{~s}$. In the tenth session (final session), the patients' balance improved noticeably, and they were able to stand on the balance board with much less vibration while their balance charts are almost similar to an average person, with the time of using the device for about $5 \mathrm{~min}$. The patient personally reported that the therapy sections with the multi-sensory balance board were useful, and his trembling and vibration decreased significantly.

Patient $\mathrm{C}$ is a 34 years old male, who has had a stroke in less than a month. Based on the symptoms and Magnetic resonance imaging (MRI), the neurologists diagnosed that the stroke damaged the nervous and sensory systems, and the patient has problems in controlling his legs. Although the patient could walk only with a walker in his first therapy session, he could stand on the balance board for about 2 minutes and 30 seconds with the help of the occupational therapist. In the tenth session (fi-

Table 1: Characteristics of people in the group.

\begin{tabular}{cccc} 
Gender of individuals & Age group & Weight $\mathbf{( K g )}$ & Type of Disorder \\
\hline Male & 30 to 40 & 80 to 90 & Stroke
\end{tabular}


nal session), the patient's balance improved significantly as he was able to walk for a short time without a walker. The neurologists recommended more therapy sessions for more improvements. On the last session, $\mathrm{t}$ the device was used for about $3 \mathrm{~min}$ and $40 \mathrm{~s}$.

\section{Discussion}

The main purpose of this project is rehabilitation of patients with various disabilities and disorders. From all the data and information gathered from the medical teams and patients, it could be easily concluded that this device was useful for the patients.

One of the abilities of multi-sensory balance board is to monitor the patients in each therapy session by giving the body balance chart.

The sense of balance in the patient's body is different from each other; thus, the reaction to imbalance can just be diverse. That is why monitoring the patient's balance can provide more information about them.

For a better understanding of the patient's rehabilitation process, the standard deviation of the results for each patient is available in the Figure 2.

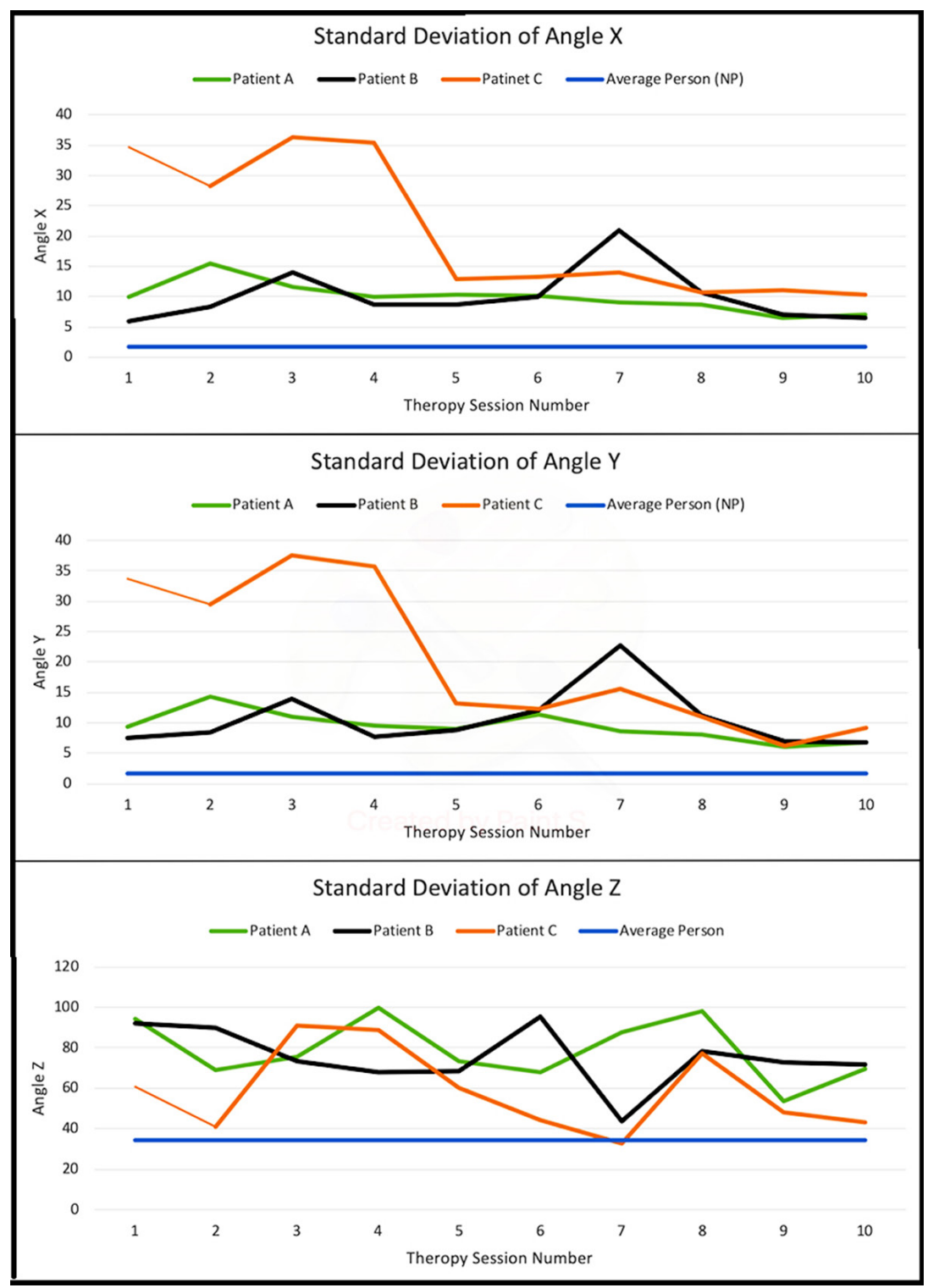

Figure 2: Standard deviation of angle X, Y, Z for patient A, B, C. 


\section{Conclusion}

The multi-Sensory balance board was designed and created by the medical community commission in collaboration with a team of mechanical, electronics, and mechatronics engineers and a medical group, including occupational therapists and doctors.

Initially, the purpose of designing this device was to help patients with multiple sensory conflicts such as SPD and ADHD. Due to the COVID 19, we suspended the implementation phase of the project, and stopped testing device on the children. Nevertheless, the tests on adults with other disabilities continued.

Based on the consultation with the medical team and the neurologists, the experiment began with stroke patients.

At present, the results of the first group, including three patients with a stroke and with similar characteristics, are available. The treatment staff reports on the project were satisfying. They replied that this device is helpful for patients and can be easily communicated. Moreover, it gives the medical team the knowledge of the present situation and helps them by tracking the patient recovery process. Also, they reported that this device indicates a balance situation and gets the patient's attention by warning them in both auditory and visual.

As the results proved the device's effectiveness, the rehabilitation center at Pars Hospital was to use the multi sensory board in long term.

Other positive points about this device are its low manufacturing cost, easy accessibility to all rehabilitation centers and hospitals.

The next step is to manufacture the device by order in different hospitals throughout Tehran in the executive phase.

One day, no one will suffer from any disease, and the lack of facilities will not harm the process of treating patients. The feedback from the doctor and the occupational therapist team were incredibly positive.
Acknowledgment

The authors want to express their gratitude to the Sharif University of Technology (Kish Island Campus) for all their supports and Dr. Masoud Mehrpour for providing us the facilities and testing platform at his private rehabilitation center.

\section{Authors' Contribution}

Amouei Sh., Mohammadi Sh. and Mohammadi Laal Abadi Z., conceived of the presented and developed the theory and performed the computations. All authors discussed the results and contributed to the final manuscript. Amouei Sh. and Mohammadi Sh. carried out the experiment. Selk Ghafari A. and Zabihollah A. helped supervise the project. Amouei Sh. contributed to the final version of the manuscript. Amouei Sh. and Zabihollah A. conceived and planned the experiments. Amouei Sh. carried out the experiments. Amouei Sh., Selk Ghafari A. and Zabihollah A. contributed to the interpretation of the results. Amouei Sh. took the lead in writing the manuscript. All authors provided critical feedback and helped shape the research, analysis and manuscript.

\section{Ethical Approval}

This study was approved by Irandoc with the code number of: 2690744.

\section{Informed Consent}

All the case study in this project entered the experiment with personal consent and were fully aware of its risks.

\section{Conflict of Interest}

None

\section{References}

1. Rust P, Hasenegger V, Englert K, König J. Improving Health of the Next Generation: Dietary Intake and Physical Activity during Pregnancy in an Austrian Cohort. Proceedings of the Nutrition Society. 2020;79(OCE2):E343. doi: 10.1017/ S0029665120002918.

2. Pouyamanesh J. The effect of bad lifestyle on increasing aggression. Procedia-Social and Behavioral Sciences. 2013;84:1634-8. doi: 10.1016/j. 
sbspro.2013.07.005.

3. Arena R, Guazzi M, Lianov L, et al. Healthy lifestyle interventions to combat noncommunicable disease-a novel nonhierarchical connectivity model for key stakeholders: a policy statement from the American Heart Association, European Society of Cardiology, European Association for Cardiovascular Prevention and Rehabilitation, and American College of Preventive Medicine. Eur Heart J. 2015;36(31):2097-109. doi: 10.1093/eurheartj/ ehv207.

4. Sturnieks DL, St George R, Lord SR. Balance disorders in the elderly. Neurophysiol Clin. 2008;38(6):467-78. doi :10.1016/j.neucli.2008.09.001. PubMed PMID: 19026966.

5. Cameron MH, Horak FB, Herndon RR, Bourdette D. Imbalance in multiple sclerosis: a result of slowed spinal somatosensory conduction. Somatosens Mot Res. 2008;25(2):113-22. doi: 10.1080/08990220802131127. PubMed PMID: 18570015. PubMed PMCID: PMC2789668.

6. Hugues A, Di Marco J, Janiaud P, et al. Efficiency of physical therapy on postural imbalance after stroke: study protocol for a systematic review and meta-analysis. BMJ Open. 2017;7(1):e013348. doi: 10.1136/bmjopen-2016-013348. PubMed PMID: 28137928. PubMed PMCID: PMC5293873.

7. Kuang D, He L. Classification on ADHD with deep learning. International Conference on Cloud Computing and Big Data; Wuhan, China: IEEE; 2014. p. 27-32. doi: 10.1109/CCBD.2014.42.

8. Scotch MD. The Experience of Children Living with Sensory Processing Disorder [dissertation]. Walden University; 2017.

9. Noll DR. Management of falls and balance disorders in the elderly. J Am Osteopath Assoc. 2013;113(1):17-22. PubMed PMID: 23329802.

10. O'Sullivan SB, Schmitz TJ, Fulk G. Physical rehabilitation. Philadelfia: FA Davis; 2019.

11. Slattery M. Diet, lifestyle, and colon cancer. Semin Gastrointest Dis. 2000;11(3):142-6. PubMed PubMed PMID: 10950460.

12. Mayo Clinic Staff. Treatment. 2020. Available from: https://www.mayoclinic.org/diseases-conditions/balance-problems/diagnosis-treatment/drc20350477.

13. Alrwaily M, Whitney SL. Vestibular rehabilitation of older adults with dizziness. Otolaryngol Clin North Am. 2011;44(2):473-96. doi: 10.1016/j. otc.2011.01.015. PubMed PMID: 21474018.

14. Wilens TE, Spencer TJ. Understanding attentiondeficit/hyperactivity disorder from childhood to adulthood. Postgrad Med. 2010;122(5):97-109. doi: 10.3810/pgm.2010.09.2206. PubMed PMID: 20861593. PubMed PMCID: PMC3724232.

15. Thapar A, Cooper M, Jefferies R, Stergiakouli E. What causes attention deficit hyperactivity disorder? Arch Dis Child. 2012;97(3):260-5. doi: 10.1136/archdischild-2011-300482. PubMed PMID: 21903599. PubMed PMCID: PMC3927422.

16. Angel T. Everything You Need to Know About ADHD, Types of ADHD. Healthline Media; 2020. Available from: https://www.healthline.com/health/ adhd/signs\#self-focused-behavior.

17. Mayo Clinic Staff. Symptoms. Mayo Foundation for Medical Education and Research; 2019. Available from: https://www.mayoclinic.org/diseases-conditions/adhd/symptoms-causes/syc-20350889.

18. Kooij JJ, Bijlenga $D$, Salerno $L$, Jaeschke R, et al. Updated European Consensus Statement on diagnosis and treatment of adult ADHD. Eur Psychiatry. 2019;56(1):14-34. doi: 10.1016/j.eurpsy.2018.11.001. PubMed PMID: 30453134.

19. Verlaet AA, Maasakkers CM, Hermans N, Savelkoul HF. Rationale for dietary antioxidant treatment of ADHD. Nutrients. 2018;10(4):405. doi: 10.3390/ nu10040405. PubMed PMID: 29587355. PubMed PMCID: PMC5946190.

20. Hethmon M, Conrad K. Understanding Disabilities: Sensory Processing Disorder. University of Tennessee; 2020. Available from: https://extension. tennessee.edu/publications/Documents/W947-H. pdf.

21. Graydon K, Van Dun B, Tomlin D, Dowell R, Rance G. Remediation of spatial processing disorder (SPD). Int J Audiol. 2018;57(5):376-84. doi: $10.1080 / 14992027.2018 .1431403$. PubMed PMID: 29378452.

22. Galiana-Simal A, Vela-Romero $M$, Romero-Vela VM, et al. Sensory processing disorder: Key points of a frequent alteration in neurodevelopmental disorders. Cogent Medicine. 2020;7(1):1736829. doi: 10.1080/2331205X.2020.1736829.

23. Sense. Sensory Processing Disorder (SPD). 2021. Available from: https://childdevelopment.com.au/ areas-of-concern/diagnoses/sensory-processingdisorder-spd/.

24. American academy of family physicians. Sensory processing disorder treatment. American academy of family physicians; 2020. Available from: https:// familydoctor.org/condition/sensory-processingdisorder-spd/.

25. Goodman B. Treatment for sensory processing disorder. WebMD; 2021. Available from: https:// 
Shila Amouei, et al

www.webmd.com/search/search_results/default. aspx?query=sensory+processing+disorder.

26. Chang M, Yee K, Nam N, et al. Relationships Between Sensory Processing and Play Experiences Among Healthy Community-Dwelling Older Adults. American Journal of Occupational Therapy. 2017;71(4_Supplement_1):7111505156p1. doi: 10.5014/ajot.2017.71S1-P07069.

27. Washburn JS. Roller board device. Google Patents; 1956.

28. McGuine TA, Keene JS. The effect of a balance training program on the risk of ankle sprains in high school athletes. Am J Sports Med.2006;34(7):110311. doi: $10.1177 / 0363546505284191$. PubMed PMID: 1647691.

29. Caraffa A, Cerulli G, Projetti M, Aisa G, Rizzo A. Prevention of anterior cruciate ligament injuries in soccer. Knee Surg Sports Traumatol Arthrosc. 1996;4(1):19-21. doi: 10.1007/BF01565992. PubMed PMID: 8963746.

30. Dayme MA. Dynamics of the singing voice. Springer Science \& Business Media; 2009. 